\title{
Televisión nacional y globalización cultural: el caso de México
}

\author{
Javier Esteinou Madrid \\ Universidad Autónoma Metropolitana - Xochimilco
}

\section{La gestación del nuevo esquema de desarrollo neoliberal}

El agotamiento del modelo de desarrollo tradicional de México seguido a lo largo de los últimos 15 años, las presiones impuestas por los bancos extranjeros para renegociar la monumental deuda externa y la consecuente crisis sociopolítica que de esto se ha derivado, provocaron que el Estado Mexicano abandonara su estrategia tradicional de consolidación interna a través del clásico esquema de substitución de importaciones seguido desde la década de los años cuarentas en el país. A partir de este momento el gobierno mexicano adoptó como salida básica de crecimiento nacional, especialmente desde 1982, el proyecto de anexión urgente al mercado mundial que propone financiar la recuperación y la expansión interna de nuestra economía a partir del incremento de las exportaciones y del aumento de inyección de capital externo.

Con este nuevo cambio en nuestra política de desarrollo, se anunció el término de la etapa paternalista y proteccionista heredada de los gobiernos pos revolucionarios que fue la fase en la que vivió inmersa la sociedad mexicana en décadas pasadas y que dio origen al Estado asistencial o Estado subsidiador, que se

* Este trabajo ganó el primer lugar en el certamen denominado "Primer Concurso Nacional de Investigación sobre Televisión", convocado por la revista Telemundo y la Dirección General de Radio, Televisión y Cinematografía (RTC) de la Secretaría de Gobernación en octubre de 1992 en la Ciudad de México, D.F. 
caracterizó por aplicar "la teoría de que el Estado ideal sería aquél en el que todo espacio social, sin faltar ningún área, debería estar subsidiado".

Dentro de este marco, se produce un cambio radical en el modelo económico tradicional de substitución de importaciones distinguido por la presencia de un complejo sistema de proteccionismos generalizados, arraigada burocracia, fuertes controles financieros, sesgo antiexportador, exenciones fiscales, enormes regulaciones legales, grandes mercados domésticos cautivos, abundancia de mano de obra a bajo costo, tasas de interés preferenciales para la promoción industrial y ausencia de competencia internacional; y se crea otro modelo industrial basado en la desregulación jurídica, la competitividad productiva, el pragmatismo financiero, la promoción mayoritaria de la inversión extranjera, la apertura comercial, el establecimiento de precios libres, la eficiencia laboral, la privatización de empresas públicas, la menor participación del Estado en la economía, el acceso abierto a todos los mercados, la intervención del sector privado en el financiamiento de la infraestructura, la acelerada transnacionalización de la infraestructura económica, el empleo intensivo de alta tecnología, el adelgazamiento de la obesidad estatal, la creciente interdependencia con los procesos económicos internacionales, la consistencia en las políticas de desarrollo gubernamental y la globalización de

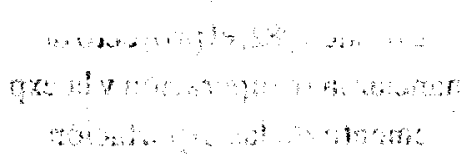

1 Salinas de Gortari, Carlos (1989): "Nos modernizamos o el cambio mundial amenaza al país: Salinas". Excélsior, 11 de abril.. Para ampliar este panorama se pueden consultar los siguientes artículos: "Urge modernizar todo el aparato productivo en bienes y servicios". (1988): Excélsior, 8 de octubre; "Describe los esfuerzos de México por integrarse a la economía mundial la carta de intensión al FMI". (1989): Excélsior, 25 de abril; "No será irrestricta, ni se hará de golpe la apertura comercial: CSG". (1989): Excélsior, 28 de abril; "Está agotado el modelo fácil". (1989): Excélsior, 9 de mayo; "En marzo la economía del país estará lista para su desregulación: Córdoba". (1989): Excélsior, 21 de junio; "Ni liberalismo a ultranza, ni estatismo ult rajante: Zedillo".(1979): Excélsior, 30 de junio; "Sucumbió el paternalismo hoy se necesita eficiencia; Peligran los avances por el déficit en paraestatales" (1989): Excélsior, 28 de julio; "La apertura comercial es una decisión permanente: Secofin". (1989): Excélsior, 16 de agosto. 
la economía para incorporarse al Nuevo Orden Económico Mundial que ha creado la Comisión Trilateral después del fin de la Guerra Fría. ${ }^{2}$

De esta forma, el Estado reconoció que las economías nacionales ya no podían actuar de manera autónoma e independiente, y que por consiguiente, nuestra sociedad ya no podía sobrevivir fuera de los nuevos procesos de globalización económicayde la división internacional del trabajoque estáimponiendola moderna

2 "Enterramos este año 'políticas populistas desquiciantes' surgidas en 1970: CCE". (1989): Excelsior, 10 de septiembre; "Fin del ciclo. Verdadera modernidad".(1989): Excellsior, 20 de septiembre; "Traumáticocambio económicode Méxicoen 10años: Banamex".(1989): Excélsior, 11 de diciembre; "Fin de la 'Guerra Fría'. Las coordenadas del Nuevo Orden". (1991): Excélsior, 9 de enero; "Termina el armamentismo que caracterizó a la guerra fría". (1991): Excélsior, 20 de enero; "Cambio de modelo industrial". (1991): Excélsior, 6 de abril; "El nuevo orden internacional". (1991): El Financiero, 18 de febrero; "Nuevo orden mundial". (1991): El Financiero, 21 de febrero; "Laberinto económico. Nuevo orden munđial". (1991): Excélsior, 24 de febrero; "El TLC no socava la soberanía y sí impide la ley de la selva". (1991): Excélsior, 6 de marzo; "i1862, 1916, 1991 ? El paso decisivo". (1991): Excélsior, 26 de julio; "De la economía de mercado". (1991): El Financiero, 28 de julio.

Por encima de la actual tendencia hacia la conformación de grandes bloques económicos y vastos mercados regionales, la Comisión Trilateral pretende la globalización de la economía, el comercio, las finanzas y la política. Así, casi 20 años después de la fundación de la Comisión el mundo se mueve hacia una de sus primeras etapas de globalización: la conformación de granđes bloques regionales económicos y comerciales. El Mercado Común Europeo, la Cuenca del Pacífico y el Tratado de Libre Comercio norteamericano son por lo pronto un primer escalón hacia la abierta globalización.

Una vez sentadas las bases: división planetaria en hemisferios norte-sur, desmantelamiento de la ideología nacionalista y reconocimiento de la economía como eje político-económico del mundo moderno, la Comisión Trilateral pretende constituirse en el centro neurálgico del poder mediante la administración de las finanzas, la economía y la tecnología a nivel global. En cuanto a la estrategia de la Comisión para cooptar al Tercer Mundo, ésta contempla 4 fases:

a.- Jerarquizar a los países en desarrollo de acuerdo con su nivel de industrialización o a su disponibilidad de recursos naturales.

b.- Otorgarles un tratamiento diferenciado en materia comercial, financiero y tecnológico en las negociaciones internacionales multilaterales.

c.- Retomar el control sobre el abastecimiento y los precios de las materias primas, sobre todo del petróleo procedente de los países en desarrollo.

d.- Presionar a los países en desarrollo avanzado como son México, Brasil y Arabia Saudita a fin de que pongan en práctica sus economías, en especial el comercio exterior, liberalizando, al mismo tiempo, sus políticas de importación y de recepción de inversiones extranjeras.

Mediante esto último pretenden llevar a cabo la reubicación de la industria internacional, de acuerdo con los intereses y prioridades de los países industrializados. Ver el artículo "La Comisión Trilateral mente maestra de la globalización", publicado en El Financiero el 28 de junio de 1991.

Dicho nuevo orden internacional estará basado en el monopolio de la fuerza de Estados Unidos, al grado de que después de la victoria sobre Kuwait y el consecuente control mundial del petróleo, éste podrá obligar a Japón y Alemania (sus principales competidores) a apoyar a la economía estadounidense. Ver "El nuevo orden basado en el monopolio de la fuerza de EU", publicado en El Financiero, el 24 de enero de 1991. 
reestructuración del Modo de Producción Capitalista a escala planetaria. ${ }^{3}$ De lo contrario, la resistencia al cambio mundial provocaría el marginamiento internacional de nuestra sociedad, a través de la suspensión de créditos externos, nula inversión de capital extranjero, retraso tecnológico, grandes presiones foráneas, convulsiones políticas internas, recesión productiva, etc.; con el consecuente estancamiento profundo de nuestra economía y la cancelación de la viabilidad del proyecto de Nación a corto y mediano plazo.

Así, se reconoció públicamente el fin de un ciclo de crecimiento nacional denominado desarrollo estabilizador que funcionó durante $\mathbf{4 0}$ años y se aceptó que era necesario entrar en un nuevo modelo de desarrollo económico, donde ahora se requiere que el aparato productivo y político se modernice para hacerle frente a la competitividad mundial o el "impetu de transformación que hoy vive el mundo arrasaría nuestra patria". 4 Especialmente, cuando después del fracaso mundial de las negociaciones de la Ronda de Uruguay y del Acuerdo General Sobre Aranceles Aduaneros y Comercio (GATT), la guerra comercial entre bloques económicos es uno de los signos centrales que determinarán los próximos tiempos. ${ }^{5}$

Para ello, el Estado Mexicano creó los procesos económicos, políticos y sociales pertinentes para que nuestro país saliera del antiguo eje trasatlántico euroamericano que ejerció la hegemonía a escala planetaria en este siglo y se integrara a la nueva reorganización profunda del capitalismo occidental, vinculándose con los tres nuevos polos del desarrollo mundial: el Mercado Común Europeo que está

3 Ver: "Globalización: El caso de México". Primera parte. (1991): El Financiero, 6 de junio; "Globalización: El caso de México". Segunda parte. (1991): El Financiero, 20 de junio; "Débil esfuerzo para integrar al país al proceso de globalización".(1991): El Financiero, 10 de junio.

4 Al respecto revisar "En 1992 el país debe estar abierto a la Comunidad Económica Europea".(1989): Unomásuno, 23 de abril; "Ofrece Europa a México más inversiones y abrir sus mercados a nuestros productos". (1989): Unomásuno, 21 de mayo; "Estamos listos para enfrentar el reto del mercado único en 1992". (1989): Excélsior, 27 de mayo; "Los logros de la gira de csG por Europa base para construir un México moderno". (1989): Unomásuno 16 de julio; "Viaje de Carlos Salinas". (1989): Unomásuno, 18 de julio de 1989.

5 Ver: "Fracaso en el GATT". (1990): El Financiero, 10 de diciembre; "Ganan fuerza los acuerdos bilaterales. El fracaso en el GATT". (1990): Excélsior, 10 de diciembre; "Nueva etapa comercial. i. Fracasó el GATT?". (1990): Excélsior, 12 de diciembre; "Regionalización: Una nueva tendencia internacional ante el fracaso de la Ronda de Uruguay y del GATT".(1991): El Financiero 28 de junio.

A partir de este fracaso las tendencias económicas que adoptarán los Estados capitalistas en la década de los noventa serán las 3 siguientes:

a.- El surgimiento y fortalecimiento de las inclinaciones proteccionistas.

b. - La presencia de grandes conflictos en materia comercial entre los países industrializados.

c.- La conformación de bloques económicos. 
compuesto por 19 países que empezarán a funcionar a partir de 1993 (Alemania Unificada, Gran Bretaña, Francia, Italia, Holanda, Bélgica, Dinamarca, Grecia, Irlanda, Luxemburgo, Portugal, España, Finlandia, Islandia, Noruega, Suecia, Suiza, Liechtenstein, Austria y los nuevos países socialistas de la Europa del Este que se anexen a este bloque); ${ }^{6}$ el Mercado Común de América del Norte que será compuesto por Estados Unidos, Canadá y México, ${ }^{7}$ y finalmente, el Mercado de la Cuenca del Pacífico formado por 24 países ribereños, 23 isleños y capitaneado por los "4 tigres asiáticos" que son Taiwán, Singapur, Hong Kong, y Corea del Sur. ${ }^{8}$

Dentro de la formación de esta nueva geopolítica mundial por bloques comerciales y políticos se observa que la tendencia de integración mayoritaria que sufrirá nuestro país, por razones geográficas e históricas, no será el vincularse en igual medida con las 3 nuevas zonas hegemónicas; sino que la inercia de nuestra añeja dependencia estructural del norte nos llevará a asimilarnos cada vez más rápido a la economía norteamericana que a la asiática y la europea, e incluso a la latinoamericana con la constitución del Mercado Común Centroamericano. Ante ello, es importante precisar que no obstante que las declaraciones oficiales señalan que "México no se propone formar parte de un bloque cerrado o hermético, ni mucho menos integrarse a un solo mercado, sino que busca lograr una amplia liberalización comercial con los cinco países centroamericanos, así como con el resto de América

6 Después del acuerdo pactado entre la Comunidad Europea y la Asociación Europea de Libre Comercio se acept 6 que el nuevo Mercado Común estuviera formado ya no por 12 países, sino por 19 abarcando desde Islandia hasta el Mediterráneo, con un promedio de 400 millones de consumidores. Ver: "Concentran 19 países Europeos un Acuerdode Libre Comercio". (1991): El Financiero, 23 de octubre; "La CEE y EFTA formarán un megamercado de 400 millones de consumidores en 93 ". (1991): Unomásuno, 23 de octubre; “Libre comercio desde Islandia hasta el Mediterráneo". (1991): Excélsior, 23 de octubre; "Dejan de lado viejas contiendas europeas". (1991): Excélsior, 24 de octubre.

Esta realidad quizá se modifique con los años pues ya existe la propuesta del Banco Europeo para la Reconstrucción y el Desarrollo (BERD), para que se cree un mercado común continental que integre a las 35 naciones de Europa y evite la desintegración de las democracias nacientes. Ver. "Un mercado común continental formado por los 35 países de Europa podría superar el nuevo bloque de Norteamérica". (1991): Unomásuno, 26 de octubre.

7 Al respecto revisar "El acuerdode libre comercioentre Estados Unidosy Canadá".(1989): Comercio Exterior, Vol. 39, No. 4, abril, México D. F., P-339, 347.

8 Ver: "Más nexos con la Cuenca del Pacífico". (1988): Unomásuno, 28 de abril; "La hegemonía en el sistema capitalista empieza a desplazarse hacia el Pacífico". (1989): Excélsior, 3 de mayo; "La Cuenca del Pacífico: Un nuevo espacio estratégico". (1988): Unomásuno, 4 de mayo; "Vitalidad regional: Cuenca del Pacífico".(1989): Excélsior, 14 de mayo; "Latinoamérica estálejos del Pacífico". (1989): Unomásuno, 19 de agosto. 
Latina, Europa y los países del Pacífico"; 9 lo cierto es que en la cotidianidad práctica nuestro proceso económico básicamente se desarrolla en función a las necesidades de la industria del norte.

Basta recordar, por ejemplo, que sólo el $70 \%$ del total anual del comercio exterior de México se realiza con los Estados Unidos, con Canadá el 1\%, con la Comunidad Económica Europea el 14\%, con las naciones de la Cuenca del Pacífico el $7 \%$ y con América Latina nada más el $6 \% .^{10}$

Por lo tanto, siendo realistas "la tesis de la integración a la economía mundial" que hoy se maneja en abstracto, significa en concreto para nuestro país la reorganización de la economía nacional con base en la dinámica de expansión de la economía norteamericana, con la que se realiza como con ninguna otra nación iberoamericana la mayor parte de nuestro comercio y de nuestras transacciones financieras.

Finalmente, para coronar todos los preparativos económicos y políticos anteriores, el Estado decidió firmar el Acuerdo Trilateral de Libre Comercio entre México, Estados Unidos y Canadá con el fin de crear el segundo mayor mercado del mundo con 360 millones de consumidores (el primero lo formará Europa con 400 millones de consumidores). Hacia la consolidación de este horizonte es por donde apuntarán la elección y realización de todas las iniciativas y esfuerzos económicos, políticos, sociales y culturales futuros del nuevo modelo de desarrollo neoliberal adoptado a partir de principios de la década de los ochenta en el país. ${ }^{11}$

\section{La cultura y la televisión ante la nueva dinámica modernizadora}

Frente a este reciente panorama histórico de formación de nuevas zonas hegemónicas, especialmente, con la formación del Tratado de Libre Comercio ente México.

9 Ver: "P. Aytwin no modificó la política económica". (1991): Excélsior, 26 de abril; "Rechaza México formar parte de un bloque cerrado: CSG". (1991): Excélsior, 7 de mayo; "Liberalización económica con 8 países". (1991): Excélsior, 9 de mayo; "Comercio más libre para evitar grupos cerrados al intercambio: Salinas".(1991): Excelsior, 2 de julio.

10 Ver: "Con la Cuenca del Pacífico 7\% del comercio de México". (1991): Excélsior, 29 de julio; "Globalización: el caso de México". (1991): El Financiero, 14 de julio; "Competencia regla del futuro". (1991) El Financiero, 26 de junio.

11 Ver: "Un Mercomún Norteamericano $25 \%$ mayor que el europeo". (1990): Excélsior, 27 de septiembre; "Con el ALC el mayor mercado del mundo".(1990): El Financiero, 25 de octubre. 
Estados Unidos y Canadá, creemos que es central y urgente preguntarnos, si con el proceso de industrialización que se genero con la substitución de importaciones de 1930 en adelante, la estructura cultural de la sociedad mexicana fue transformada rápidamente por la radio y la televisión para crear una mentalidad consumista, desparticipativa y una erosión de nuestra identidad nacional; ahora, ¿qué nos sucederá espiritualmente como sociedad y como individuos al entrar a la fase de integración mundial y vincularnos de forma acelerada con el mercado internacional sin planificar el uso de nuestros medios de comunicación, especialmente de la televisión? ¿Qué acontecerá con nuestras estructuras de pensamiento y sentimientos cuando el país vive una etapa de retroceso cultural, de pérdida de memoria histórica y de inmadurez cerebral; y ahora, con el Tratado de Libre Comercio, se incrementará la saturación ideológica de nuestra base cultural por medio de la acción de las redes de televisión y del complejo del video de los nuevos bloques comerciales que actuarán sobre nuestra sociedad? ¿Cómo conservar el proyecto cultural independiente del Estado Nación Mexiçano en una atmósfera de creciente globalización comunicativa, de apertura de fronteras mentales y de formación de culturas supranacionales? ¿Qué va a ganar y qué va a perder culturalmente México con la firmadel Tratadode Libre Comercio? ¿Qué tanto la nueva estructura cultural e informativa que está creando la modernidad, sirve para que nuestra sociedad verdaderamente se desarrolle y crezca material y espiritualmente? ¿Qué aspectos de la cultura nacional deben ser negociados y cuáles no ante el Acuerdo Trilateral de Libre Comercio?

De aquí, la necesidad urgente de reflexionar sobre nuestra cultura y la acción de los medios de comunicación, particularmente de la televisión, para conservar su esencia nacional dentro de la dinámica de acelerado cambio modernizador que vive el país; pues el proceso de la globalización mundial nos lleva a la creación de un nuevo orden cultural que modificará los contenidos y las fronteras ideológicas de los actuales Estados nacionales. De lo contrario, el alma cultural de nuestra sociedad correrá el gran riesgo de quedar sepultada por los nuevos espejismos de la modernidad y sus derivados simbólicos parasitarios de esta nueva fase del desarrollo de la sociedad capitalista internacional.

Ante esta realidad pensamos, que por la irresponsabilidad que se mostró al no planificar el uso de los medios electrónicos en las últimas tres décadas, la falta de voluntad política para formar desde los canales masivos una cultura para el desarrollo, la debilidad de los gobiernos poscardenistas para defender la cultura 
nacional, y la complicidad de las autoridades públicas ante la penetración del proyecto transnacional en el terreno psíquico; hoy el Estado Mexicano ha perdido un enorme terreno para formar, a través de las industrias electrónicas, un fuerte nacionalismo, una sólida identidad y cohesión nacional que sirvieran como punto de despegue para el proyecto de crecimiento interno. Esto, a menos de que sucedan en nuestro país profundos cambios políticos que renueven la posibilidad de retomar los intentos de desarrollo autónomo, independiente y democrático que hoy parece que se han pospuesto.

Es decir, sin conocer y asimilar todavía a fondo las alteraciones culturales que nos produjo la Conquista Española hace 480 años y las mutaciones mentales que nos ocasionó desde la década de los años cincuenta la presencia de la sociedad de consumo con el proyecto de sustitución de importaciones durante la industrialización nacional; ahora, nuevamente sin estar preparados culturalmente nos vuelve a sorprender la profunda dinámica de la reestructuración económica, política e ideológica mundial con la ola modemizante y nuestra sociedad, una vez más, se incorpora a ese proceso sin la creación de un proyecto cerebral propio. Así, sin haber terminado de definir su proyecto nacional y $\sin$ haber resuelto sus conflictos de país subdesarrollado; la sociedad mexicana de nuevo es arrastrada por la dinámica del capitalismo altamente avanzado para construir otro modelo de desarrollo internacional y encajarse en los huecos marginales que deja esta profundísima transformación planetaria.

\section{Los medios de comunicación ante la apertura y la globalización nacional}

Dentro del modelo de desarrollo moderno que ha adoptado nuestro país a través del establecimiento del Tratado de Libre Comercio, debemos tener presente que para que éste se consolide no sólo requiere, a nivel infraestructural, la transformación de los procesos productivos y la modificación de la estructura de las vías materiales de transporte; sino que también demanda, a nivel supraestructural, la adecuación profunda de los medios de comunicación simbólicos a las nuevas condiciones económicas que han surgido. Esto significa, que la apertura de fronteras nacionales a los nuevos mercados mundiales no sólo exige, en primer término, producir las mercancías y servicios con competitividad, y en segundo término, transportarlos con eficiencia del lugar de su manufactura a su zona de 
venta; sino que, obligatoriamente, también necesita, en tercer término, anunciarlas masivamente para que puedan ser consumidas.

Vinculando este horizonte con los medios de comunicación, encontramos que aunque en términos de hechos (no de discurso) los canales de información y en particular la televisión se encuentran todavía muy desfasados del proyecto modernizador, pues éste se ha dado ampliamente en el campo económico normativo, un poco en el político-cultural y casi nada en el terreno comunicativo; sabemos que para que el modelo de desarrollo neoliberal se pueda realizar en México, es indispensable la presencia de nuevas condiciones legales, productivas, tecnológicas, laborales, jurídicas, etc., pero además exige la presencia insustituible de una nueva conciencia masiva neoliberal que respalde y afiance las acciones anteriores. Dicha conciencia intentará producir, a través de los medios electrónicos de comunicación, las condiciones subjetivas necesarias para el funcionamiento de nuestra sociedad dentro de las nuevas relaciones competitivas del mercado mundial.

De esta forma, así como el capitalismo mexicano para afianzarse en su fase de industrialización creó a mediados del siglo $\mathrm{xx}$ un tejido cultural consumista que con el tiempo se convirtió en la religión de las ciudades, desde la cual los individuos construimos gran parte de nuestro sentido más profundo para vivir y apoyamos el modelo de acumulación material; ahora, el capitalismo modernizador para consolidarse en su etapa neoliberal de apertura de fronteras requiere producir otros rasgos de la identidad nacional a través de una nueva estructura de valores algunos de cuyos puntales son la eficiencia, la tecnificación, el pragmatismo, la supercompetencia, la privatización, la obsolescencia, la desregulación, la desestatalización, la internacionalización, la globalización, etc.

Nueva estructura axiológica que se distinguirá por cancelar los valores del antiguo Estado del bienestar nacional generado a partir de la Revolución de 1910, e introducir los valores del moderno Estado neoliberal que mantiene como centro de gravedad el laisse faire del proyecto de acumulación ampliada en el campo de la comunicación, la cultura, la conciencia y el espíritu.

En este sentido, podemos decir que sobre las bases del primer sincretismo cultural que realizó nuestro país en el siglo $\mathrm{XX}$ con la sociedad norteamericana después de la Segunda Guerra Mundial; ahora iniciamos otro segundo sincretismo con la cultura norteamericana a partir de la formación del Tratado de Libre Comercio y la presencia intensiva de la ideología de la modernidad en nuestra 
sociedad. Es decir, con la incorporación de nuestra sociedad a los procesos de globalización internacional no comienza la penetración cultural, la pérdida de identidad nacional y la instauración de los principios capitalistas en el campo de nuestra conciencia colectiva; pero sí se inicia a través de las industrias culturales, y en particular de la television, una nueva fase acelerada de inversión de valores nacionales mediante la circulación de nuevas ideologías para apuntalar el fortalecimiento del sistema productivo y la distribución desregulada de mercancías que exige el moderno programa de crecimiento neoliberal que ha elegido seguir el sector cúpula del Estado Mexicano para las próximas décadas.

De esta forma, podemos afirmar que con la globalización se intensificará la proliferación de diversos órdenes y expectativas pragmáticas del conocimiento y de la vida. En particular, "se da un mayor énfasis científico y tecnológico en nuestra tradición intelectual; que hasta el momento ha sido más propicia a la influencia de la cultura humanista y jurídica". 12

Así, proyectando sobre el campo de la conciencia colectiva las determinantes estructurales que gradualmente impondrá el nuevo programa de crecimiento nacional, catalizado por el Tratado Trilateral de Libre Comercio, observamos que la moderna subjetividad que producirán los medios electrónicos en el futuro estará caracterizada, en parte, por fomentar el individualismo por sobre las relaciones solidarias. Acentuar la competitividad por sobre el trabajo compartido (Tequio). El canibalismo salvaje por sobre la fraternidad. La marcada admiración por lo extranjero que por lo nacional. El interés por la no planificación colectiva sino por la altamente privatizada. La lucha por la libertad y felicidad aislada y no por la grupal. El valor supremo de la eficiencia por sobre otras metas humanas superiores. El abandono de los valores tradicionales para asimilar los modernos. El dinero como base del reconocimiento y la valoración social. El hedonismo y la cultura del Yo, como nuevo cristal para mirar la vida. La tecnificación extrema como sentido del éxito y no el diálogo y el acercamiento humano, etcétera.

De esta manera, a partir de la presencia del proyecto neoliberal en la sociedad mexicana nos enfrentamos a la redefinición y cambio profundo de nuestra identidad psíquica, cultural y humana como sociedad pluriétnica y pluricultural; para ahora incorporar otros marcos de cosmovisión y de prácticas de la existencia desde las

12 Ver. "Las culturas aisladas perecen; sólo las comunicadas sobreviven: Fuentes".(1991): La Jomada, 20 de julio. 
premisas de la modemidad. Bases de visión de la vida que no son otra realidad que la mirada de la reproducción ampliada del capital a escala planetaria.

Ello debido a que las lcyes internacionales del nucvo patrón de acumulación de capital que se cstá gestando y que permean todos los niveles de la sociedad, están exigiendo en la esfera cultural que el alma colectiva que se construya en el país a través de los canales clectrónicos de información, se base en una visión de la vida más cosificada y transnacionalizada que nos lleve a saber cada vez más del gran mundo exlerno y cada día menos de nosotros como República y como personas. En una idca, sc busca producir culturalmentc a los hombres universales y a los ciudadanos del mundo, capaces de consumir cualquicr mercancía producida por los acuerdos comerciales de los nucvos bloques hegemónicos. No debemos olvidar que la expansión de la cconomía multinacional obliga crecientemente a crear un globul sitpermarket para reproducirse a escala ampliada en todo el planeta, ante lo cual la cxistencia de Estados nacionales yde políticas culturales regionales aparecen como un fucrte estorbo que hay que superar. ${ }^{13}$

En este sentido, nuestra sociedad hoy vive una profunda contradicción en su alma cultural, pucs micntras en cl fondo cl México profundo o nucstra civilización negada compucsta por una milenaria rcalidad pluriétnica y pluricultural, silenciosamentc, lucha por reafirmarse y expresarsc; cl México de la modernidad o cl México imaginario que se incorpora a la dinámica de la globalización oligopólica, pretende homogencizar, estandarizar y masificar las manifestaciones culturales y los gustos en la comida, las expresioncs, la música, los bailes, cl vestido, las tradiciones, los afectos, los valores, en una idea, el universo de la vida cotidiana, para crear condiciones más propicias para la expansión del mercado supertransnacional en nuestra socicdad. ${ }^{14}$ Por ol ra parte, rcforzando la misma orientación encontramos que en la superficic simbólica de la sociedad mexicana los discursos oficiales del gobicrno y de los grandes empresarios señalan que "la firma del Tratado de Libre Comercio con Estados Unidos y Canadá no menguarán la soberanía ideológica". ${ }^{15}$

13 Ver: "Nucstro ret raso social, no tecnológico". (1989): Excellsior. 30 de mayo.

14 Ver: "Reto incorporar modernidad con identidad Énica". (1991): Fixcelsior, 4 de julio. 
Sin embargo, pese a que en la fachada de nuestra sociedad se presentan las declaraciones oficiales anteriores sobre la intrascendencia del Tratado de Libre Comercio en nuestra cultura nacional; lo cierto es que, en realidad, en las entrañas de nuestra vida cotidiana hoy estamos ante el silencioso embate de nuestras culturas y diferencias ideológicas tradicionales para destruirlas o reacomodarlas dentro del nuevo esquema de división del mundo por modernos bloques hegemónicos. Recomposición mental que gradual y silenciosamente está unificando los campos imaginarios, las aspiraciones profundas y las cosmovisiones de los seres a través de la construcción de un nuevo concepto de relaciones humanas, de placer, de triunfo, de trabajo, de felicidad, de moral, de religión, de etnia, etc., en una idea, de un nuevo sentido y estilo de vida determinado por las nuevas exigencias de maduración del comercio mundial. Situación que se condensa en la creación del nuevo México imaginario de la fase de la globalización mundial, que se opone al México profundo y real de finales del siglo XX.

Ante ello, es conveniente considerar que si la historia de la publicidad en México a lo largo de los últimos 40 años ha demostrado que con tal de vender las mercancías para acelerar el proceso de circulación del capital, ésta estuvo dispuesta a banalizar e incluso prostituir finamente la imagen de la mujer para presentarla fundamentalmente como un objeto de uso sexual, a añadirle cualidades falsas ofetichizar los productos para hacerlos más atractivos, a crear necesidades artificiales en los consumidores para alentar la compra, a hacer creer que el valor de las personas se deriva de la marca que eligen y no en el porcentaje en que se conocen a sí mismos, a impulsar que el éxito de los individuos se da en la medida en que se acumulan pertenencias y no en el grado en que se es humano, a modificar la identidad nacional para revalorarse socialmente a través de la adquisición progresiva de más productos transnacionales, etcétera; ahora, es posible pensar que al entrar en la fase de

15 Ver: "Los atrasos económicos y tecnológicos provocan la pérdida de soberanía e identidad". (1991): El Financiero, 20 de junio; "No menguará el TLC soberanía ni cultura: Serra Puche". (1991): El Financiero, 21 de junio.

Esta posición ha llegado a tal extremo, que el titular de la Secretaría de Comercio, el Lic. Serra Puche, ha declarado que en las negociaciones del Tratado de Libre Comercio el caso de la cultura noes importante. Es más, se indica que dentrode este contexto trilateral "no hablamos del problema de la cultura, sino de que haya programas. Tenemos nuestras restricciones, los americanos y los canadienses las suyas. Lo que es cierto es que el cambio tecnológico está ocurriendo a una velocidad tal que será muy difícil detener programaciones porque van a llegar por medio de antenas parabólicas. Entonces eso es cosa de sentarnos a ver este asunto con una actitud moderna". Ver: "México no acepta un TLC con sólo buenas intenciones". (1991): Excélsior, 12 de septiembre. 
desarrollo de libres fronteras se construirá masivamente a través de las industrias culturales una visión del hombre y de la vida cada vez más condicionada por los requerimientos de expansión y fortalecimiento del mercado universal y no de la humanización de los individuos.

\section{El surgimiento del neoconsumo nacional}

Motivado por la necesidad de movilizar el enorme flujo de mercancías que acceden al país por la apertura de fronteras comerciales a través de la incorporación de nuestra sociedad al Sistema General de Aranceles y Comercio (GATT) y de la firma del Tratado de Libre Comercio, se produce en nuestra República a través de la televisión una nueva mentalidad neoconsumista que actúa como cemento de identidad que articula a las clases sociales. Dicha ideología se caracteriza por introducir la propuesta que plantea que para ser modernos, estar al día y mantenerse adaptados a la permanente dinámica de cambio que se vive en el mundo, hay que consumir constantemente los nuevos productos, especialmente extranjeros, que produce la modernidad: consumo, igual a progreso social.

De esta forma, la apertura económica del mercado mexicano produce una acelerada modernización del consumo nacional, ya que la sociedad mexicana, sin estar preparada, ahora produce muchos productos que se venden en otras latitudes. Así, comparando la vinculación que se da entre producción, innovación y consumo, observamos que en relación con el consumo se ha dado un disparo brutal en la velocidad de reacción de los consumidores que se han lanzado a la adquisición de los productos importados; mientras que la velocidad de reacción de las empresas nacionales para producir los bienes que se requieren es 100 veces menor, y la velocidad de la industria para introducir innovaciones es 1,000 veces menor. De esta manera, con la introducción del proyecto neoliberal en el país se configura un mercado moderno de consumo, antes que una infraestructura de producción e innovación industrial. ${ }^{16}$

Esta realidad plantea la seria posibilidad de que nuestra sociedad se convierta en una simple bodega o un mega supermercado transnacional receptor de los productos, especialmente chatarras, elaborados fuera del país, con nula o reduci-

16 Ver: "La apertura comercial sólo trajo modernización en el consumo, aseguran varias instituciones". (1991): El Financiero, 15 de octubre. 
dísima capacidad de producción propia. Panorama que puede sintetizarse precisando que ante la apertura México tiende a convertirse, cada vez más, en un país consumidor, y dejar de ser una Nación productora de bienes, con la consecuente disminución o desaparición de la planta productiva frente a la salvaje competencia mundial. ${ }^{17}$

Ante este contexto psíquico colectivo parecería como si las nuevas mercancías que nos provienen del exterior estuvieran actuando otra vez sobre nuestra conciencia como las lentejuelas y las cuentas de vidrio que utilizaron los primeros conquistadores para cambiar nuestros metales preciosos por baratijas extrañas.

En este sentido, podemos afirmar que a unos meses de festejar el aniversario de los 500 años del descubrimiento yla evangelización de América por los españoles, especialmente después de la firma de los preparativos para el Acuerdo del libre Comercio con Norteamérica; hoy vivimos en el campo de nuestra identidad una segundaevangelización comercial silenciosa, a través de los medios de comunicación electrónicos y de otras infraestructuras culturales para convertirnos, desde las leyes del mercado en MEX - USA, y subordinarnos ya no al devenir español, sino ahora a la propuesta del "destino manifiesto" americano.

\section{La cultura en los tiempos del Tratado de Libre Comercio}

La oscuridad ante el retroceso del proceso de comunicación que vivimos en el país, nosólo es responsabilidad de nuestro gremio profesional, sino ante todo del Estado Mexicano, quien ante este panorama cada vez más aniquilador del nivel de calidad de vida, en lugar de producirlo a través de los medios electrónicos y de otras infraestructuras mentales una cultura profundamente humana que es una de las demandas más intensas que se palpa en las necesidades de los grupos sociales después de un largo período de derrumbe del interior de nuestra comunidad; hoy entramos en la salvaje propuesta de aceptar indiscriminadamente los principios de la cultura neoliberal. Bases que en la práctica real plantean que en vez de

17 Ver: “'Grave proceso consumista' en México por la apertura comercial: SIPPE”. (1990): Unomásuno, 15 de octubre; "Con eso de la apertura comercial hay que comprar de todo". (1991): Excélsior, 7 de mayo; "Riesgo de que México sea una bodega de productos extranjeros". (1991): El Financiero, 12 de junio. 
fortalecer nuestro espíritu nacional frente a este período de apertura cultural, éste erosione más sus valores para incorporarnos eficientemente y sin restricción alguna a la nueva estructura de competencia de los mercados mundiales.

Es decir, ante el florecimiento en nuestro país de las tesis neoliberales que sostienen el adelgazamiento, la privatización, el retiro, la desregulación, la globalización y la transnacionalización de todos los campos de lo público; hoy se formula, cada vez más, con mayor convencimiento que la rectoría cultural de la sociedad mexicana no debe conducirse por la acción interventora del Estado, sino por el equilibrio natural y perfecto que produce el juego de las libres reglas del mercado entre productores y consumidores. De esta forma, para adecuar el espacio cultural de la sociedad mexicana a las nuevas necesidades del mercado, se altera la concepción tradicional de la actividad comunicativa que la comprendía como un producto social y se pasa, con mayor velocidad, a entenderla ahora como una simple mercancía más que debe estar regida por los principios de la oferta y la demanda.

Dentro del nuevo contexto de cambio nacional que vive la sociedad mexicana que se caracteriza porque ésta es dirigida por las leyes del mercado por encima de otros principios de desarrollo; se argumenta que para conducir culturalmente al país, antes hay que modernizar a los medios de comunicación, y en particular a la televisión, a través de volverlos eficientes. Nueva eficacia que se entiende no como el acto de producir un crecimiento de la conciencia social de la población frente a las trabas que le impiden avanzar; sino como la tarea de alcanzar el simple grado de autosuficiencia económica en los medios gubernamentales a costa del precio cultural que sea.

Realidad que con tal de lograr el autofinanciamiento económico que exige el nuevo modelo neoliberal, ha renunciado al contenido más elemental de la comunicación; para ahora trasladar los modelos productivistas al campo de ésta y concebirla modemamente en el sentido más instrumental posible, como un simple intercambio de relaciones entre máquinas y no como la gestación de procesos creativos que generen la participación, el acercamiento, el descubrimiento, la aceptación, la colaboración y la transformación de los individuos y de los grupos entre sí, para humanizarse más y trascender. Así, el proyecto modemizador ha entendido y practicado superficial y autoritariamente la comunicación como un mero traslado de información de un sector a otro y no como un fenómeno de crecimiento de la conciencia colectiva para descubrir con claridad qué significa ser Hombre. Por consiguiente, se piensa que mientras más datos se transfieran de 
un área a otra a través de cerebros electrónicos bancos de datos, satélites, fibras ópticas, video conferencias, teléfonos, microondas, etc., se será una persona, un grupo o un país más modemo.

De esta forma, en lugar de reflexionar y proponer cómo los medios estatales de comunicación pueden colaborar a impulsar el desarrollo del país a través de la producción de los nuevos niveles de conciencia colectiva que requiere el urgente proyecto de crecimiento de la sociedad mexicana; la propuesta neoliberal anula la raquítica función social de pronioción de la cultura, impulso a la ceducación, aliciente a la participación democrática, fomento a la conscientización, apertura a la pluralidad, etc., que de forma débil diariamente desempeñaron éstos en años anteriores, y ahora los convierte bajo el velo de la modemidad en medios de realización intensiva del proceso de circulación capital al volverlos prioritariamente aceleradores del circuito de venta de las mercancías. Por lo tanto, al permitir que cada vez más los medios estatales sean gobernados por las leyes del mercado y no por las directrices de la planificación nacional del crecimiento cercbral, emotivo y espiritual de la población; el Estado Mexicano abandona paulatina y silenciosamente su obligación social de crear las condiciones subjetivas para el crecimiento equilibrado, que anémicamente ejerció en el pasado vía éstos; para ahora dar paso libre a la acción de las primitivas leyes del capital en el campo de la cultura y la conciencia.

En este sentido, podemos decir que con la modernización neoliberal cl Estado Mexicano renuncia cualitativamente a la conservación de su alma cultural, propiciando el fin ideológico del Estado-Nación y entrega nuestro proyecto cultural y comunicativo a los intereses del mercado salvaje que crean los monopolios nacionales y transnacionales, con el fin de incorporarse ágilmente al proyecto mundial de la nueva acumulación y concentración de la riqueza por bloques económicos planetarios.

No debemos olvidar que las enseñanzas de la historia mental del país han mostrado que a todo profundo cambio económico ocurrido en nuestra sociedad le ha seguido la realización de una paralela transformación cultural. Por ello, pensamos que para que se pueda realizar el paso acelcrado de la creciente liberalización de nuestra economía, tarde o temprano, se exigirá la liberación igualmente progresiva de nuestras fronteras culturales a través de los avanzados medios electrónicos, especialmente, de la televisión: una sociedad abierta a la 
globalidad internacional en el campo económico, necesariamente requiere contar con una apertura cultural del mismo grado para poder funcionar armónicamente.

\section{Los nuevos obstáculos}

La presencia de los principios de mercado sobre el proceso de funcionamiento de la comunicación, significa que la opción para construir vía la televisión una mentalidad colectiva de carácter preventivo o correctivo frente a nuestros grandes problemas de desarrollo nacional como son la protección ecológica, la producción de alimentos, la atención a los sectores marginados, la promoción de la mujer, la aceptación de los grupos indígenas que son los fundadores de este territorio, la conservación de especies naturales, la atención de los ancianos, el combate a la erosión de la tierra, etc., en una idea, el impulso a una cerebralidad social más desarrollada; cada vez será más difícil lograrla vía las industrias culturales, pues éstas son áreas poco rentables para las leyes del mercado que progresivamente gobernarán más el proyecto de la televisión pública. ${ }^{18}$ Es decir, debido a que la nueva forma de financiamiento que plantea el modelo neoliberal lleva a que los medios gubernamentales se comercialicen más, y por lo tanto, sean los patrocinadores quienes determinen el contenido de transmisión de los canales, será cada vez más difícil promover una cultura de desarrollo social desde éstos, pues el esquema de sostenimiento de dichas empresas buscará crecientemente la obtención de la máxima ganancia monetaria a corto plazo.

Por consiguiente, se puede pensar que debido a las profundas transformaciones urbanas que se han dado al interior de la población nacional a la desarticulación, global que vive el proyecto cultural gubernamental, a los avances tecnológicos que se han conquistado en el terreno audiovisual y a la renuncia del Estado Mexicano para ejercer la real conducción mental del país, la dirección cultural de la sociedad mexicana, especialmente, de las clases medias metropolitanas, será realizada, cada

18 Sobre este punto, el director de IMEVISION señala que el consorcio "aspirará a no ser una carga financiera para el Estado, sino a incrementar la calidad de las transmisiones para ser un medio eficaz en la promoción de productos y servicios, para ser una empresa próspera financieramente hablando... Ante todo IMEVISION busca ser una compañía prósperamente rentable, por lo cual el perfil de los canales de la emisora será el de una televisión de calidad que tienda a convertirse en un atractivo para las inversiones publicitarias". Ver: "La primera competencia que debemos ganar debe ser ante nosotros mismos: Alvarez Lima". (1988): Unomásuno, 11 de diciembre. 
vez más, desde las industrias audiovisuales, particularmente, transnacionales. Situación que en la medida en que se consolide llevará al país a una mayor dependencia estructural del exterior y en algunos casos a la parálisis cultural, pues crecientemente conoceremos más sobre lo secundario y no sobre lo central para nuestro desarrollo. Realidad que en el grado en el que se afiance acentuará nuestra crisis nacional, y por consiguiente, ahondará nuestro estado generalizado de infelicidad humana.

Ante esta realidad comunicativa observamos cotidianamente la presencia de un Estado Mexicano crecientemente más débil, pues no cuenta con un proyecto cultural para la rectoría de los medios de comunicación electrónicos, particularmente de la televisión; sino que él mismo los ha abandonado, mayoritariamente, a los caprichos de las libres fuerzas del mercado interno y externo. Esto es, ante el financiamiento crecientemente mercantil de los medios de comunicación hoy somos cada vez más testigos de la derrota del proyecto cultural del Estado y de la sociedad civil en el terreno cerebral para mantener y ampliar el programa de identidad y democratización nacional a través de la superestructura audiovisual de la República.

En este sentido, presenciamos que contrariamente a las tesis modernizadoras del Estado Mexicano que plantean que éste se desregula y se privatiza para ya no ser más un Estado propietario, sino una entidad orientadora y directora de la sociedad; en la práctica constatamos que en el terreno cultural el Estado se ha convertido en una realidad progresivamente más endeble que no tiene capacidad para dirigir a la sociedad mexicana hacia un proyecto cultural propio y autónomo.

Bajo esta perspectiva, podemos decir que "el México profundo está de nuevo bajo el riguroso control del México imaginario que, como pocas veces, ha hecho suyo el proyecto de las potencias dominantes. Sin embargo, ese México profundo sigue vivo y su contradicción con el México imaginario no ha desaparecido, sino todo lo contrario se ha agudizado". 19

19 Ver: “El 'México Profundo' sigue vivo”. (1991): Excélsior, 31 de julio. 


\section{¿Qué hacer? Hacia la formación de una nueva política nacional de cultura y comunicación}

Considerando el retiro progresivo del modelo público de televisión en el país y de los proyectos culturales de asistencia social, creemos que ante la anexión cada vez más acelerada de nuestra sociedad a las leyes culturales del mercado internacional que se está dando a través de nuestra vinculación con el Sistema General de Aranceles y Comercio (GATT), de la apertura a los países de la Cuenca del Pacífico, de la integración muy dinámica a la economía norteamericana y canadiense a través de la firma del Tratado de Libre Comercio y de la relación con el nuevo Mercado Común Europeo para 1992; si el Estado Mexicano no construye un proyecto cultural nacional crecientemente más sólido, a través del empleo racional de los medios de comunicación electrónicos, y en particular, de la televisión, estará cavando su propia tumba, de forma cada vez más profunda. Esto, debido a que permitirá que se destruyan en la conciencia de la población las bases mentales que requiere mantener para existir como Estado Nacional.

Destrucción que rápidamente tiende a acentuarse pues el proyecto neoliberal delEstado presiona para que los medios de comunicación funcionen como negocios y no como servicio público. Especialmente, cuando en esta fase de modernización las leyes del mercado atraviesan de manera más profunda la estructura de los canales de información; y por consiguiente, son las fuerzas de la libre competencia las que ascendentemente gobiernan el proyecto cultural de las industrias audiovisuales y no el proyecto de desarrollo social y humano de la población.

De aquí, la importancia estratégica de reactivar prioritariamente el liderazgo delEstado desde su avanzada cultural y no desde las simples trincheras económicas tradicionales que lo que hacen es subordinar la vocación de expansión universal del espíritu nacional a las necesidades coyunturales de reproducción del capital. No podemos olvidar que no hay Nación que se desarrolle que no tenga una conciencia nacional fuerte y en ese sentido detrás del nacionalismo mexicano hoy existe una ausencia de integración nacional.

Por ello, ante el sistema de contenidos de los medios de comunicación electrónicos altamente desintegradores del país, pues no fomentan la participación democrática, ni la expresión de la pluralidad de opiniones, y por lo tanto, la formación de una conciencia crítica; la única forma de enfrentar la vertiginosa 
transformación mental que se nos viene con la liberación de fronteras, es la construcción de una sólida política nacionalista de comunicación para el país.

Pensamos que la única forma de saltar sanamente hacia la modernidad que nos impone la dinámica de evolución mundial es asimilar el cambio desde los marcos del conocimiento profundo de nuestra cultura y no desde los seductores espejismos modernizantes que en el campo del desarrollo se esfuerzan por proponernos los países avanzados y nuestras élites nacionales para fortalecer su estructura de hegemonía y de acumulación material.

Es decir, para abrirnos al exterior de manera madura y no volvernos a perder como sociedad en el mar de las opciones del progreso tecnologizante y civilizado que nos ofrece el glamour de la modemidad, es requisito indispensable profundizar en el conocimiento de quiénes somos como sociedad, qué riqueza tenemos, cuáles son nuestras necesidades y qué alternativas de solución tenemos frente a ellas. De lo contrario, nos relacionaremos en desventaja con una dinámica que produce infinitas ilusiones sobre loque es el desarrolloy que por consiguientc históricamente nos atrapará una vez más.

Ante ello, debemos preguntarnos ¿qué nos sucederá como sociedad si nos vinculamos en un acuerdo de libre comercio con el exterior con una base cultural deprimida y erosionada como hoy la tenemos? ¿Con qué actitudes y normas debemos relacionarnos con las seductoras dinámicas culturales externas, cuando somos un país que tiene una media mental de 6 años de primaria, una deserción escolar en educación básica cercana al $45 \%$, una inversión en ciencia y tecnología inferior al $0.52 \%$ del Producto Interno Bruto, una infraestructura nacional de sólo 2,000 bibliotecas públicas, es decir una sala de lectura por cada 41 bares, una planta humana de 22 investigadores por cada 100 mil habitantes, una escuela por cada 10 cantinas, una creciente fuga de cerebros, un ausentismo escolar que produce una pérdida anual de 1,500 millones de dólares?, etcétera.

Ante esta situación, es necesario tener presente que para que la sociedad mexicana se desarrolle a través del modemo Estado Mexicano, especialmente, en los tiempos del Tratado de Libre Comercio, es necesario aplicar muchas acciones administrativas, legislativas, políticas, infraestructurales, organizativas, etcétcra; pero además de estas actividades a nivel material, es indispensable ejecutar intensos y muy sólidos proyectos culturales orgánicos que respalden las acciones de gobierno y desarrollo nacional. Para ello, es central que el Estado Mexicano abandone sus tradicionales desviaciones aristocráticas, folkloristas, elitistas y culturalistas que ha 
practicado durante varias décadas y que han entendido la acción cultural de forma restringida como la expresión de las sensibilidades más refinadas en todos los órdenes de las artes y de los conocimiento; y la replantee ahora en un sentido amplio como la producción de una nueva Cultura Orgánica que responda a las principales problemáticas cotidianas que la sociedad mexicana tiene que resolver para sobrevivir.

Ello significa, que el Estado Mexicano debe fundamentalmente canalizar la mayoría de su energía financiera, material, artística y espiritual hacia la producción de una nueva cultura agrícola para la producción de alimentos que disminuya las más de 9 mil toneladas de nutrientes que actualmente importamos para existir. Una nueva cultura natural que evite que se sigan destruyendo más de 200 especies animales y vegetales que se han aniquilado en lo que va de este siglo en nuestra República. Una nueva cultura local que aminore la migración de más de $10 \mathrm{mil}$ personas diarias a las principales ciudades del país. Una nueva cultura forestal que disminuya la erosión de más de 500 mil hectáreas anuales que se destruyen en nuestra reserva territorial. Una nueva cultura acuífera que permita darle una valor racional al agua para aprovecharla civilizadamente y ahorrar el $30 \%$ del líquido potable que hoy se desperdicia irresponsablemente en las urbes. Una nueva cultura ecológica que contribuya a disminuir las más de 6,000 toneladas diarias de partículas contaminantes que se acumulan en la atmósfera del Valle de Méxicoy las principales ciudades del país, y que silenciosamente cada vez más nos suprimen la vida.

Una nueva cultura femenina que permita la amplia participación social de las mujeres mexicanas que son el $50 \%$ de la población nacional. Una nueva cultura energética que nos lleve a vivir lo más justamente la transición por la que atraviesa el país al pasar de la era del petróleo a otra fase de desarrollo motriz. Una nueva cultura nutricional que posibilite disminuir la inanición en más del $60 \%$ de la población nacional, especialmente infantil, que permanentemente vive sin los mínimos alimenticios requeridos para sobrevivir. Una nueva cultura de la organización que integre alrededor de nuestros conflictos sociales básicos a los 85 millones de habitantes que vivimos en el país, pues todavía somos una sociedad que está por organizarse plenamente. Una nueva cultura que permita valorar y amar profundamente lo mexicano para afirmar nuestra cada vez más débil identidad nacional y evitar la rapidísima pérdida de nuestro proyecto cultural del país ante la apertura de fronteras. Una nueva cultura para las emergencias nacionales, especialmente, de naturaleza sísmica en el Valle de México cuando sabemos que 
los especialistas sismólogos de la Universidad Nacional Autónoma de México han anticipado la presencia de fuertes movimientos de las capas telúricas para los próximos años como ya se comprobó, una vez más, con el temblor de 6 grados en la escala de Richter del 25 de abril de 1989, etcétera. ${ }^{20}$

Hoy, es indispensable considerar que la edificación del nuevo Estado Mexicano no se puede construir sobre la base de los viejos valores sociales, especialmente, cuando fueron dichos principios los que nos llevaron a la profunda crisis estructural que actualmente vivimos. En esta coyuntura es indispensable reconocer que el verdadero Estado Moderno, no surge de la realización de simples cambios administrativos, de las aperturas políticas, de las transformaciones tecnológicas, de la apertura a la inversión extranjera, del adelgazamiento gubernamental, de las modificaciones de la retórica oficial, etcétera, sino que, en última instancia, parte del cambio mental de la población.

Esto es, las verdaderas bases del Moderno Estado Mexicano tienen que surgir de la profundidad y coherencia que posea su proyecto cultural y no de las simples respuestas coyunturales atrevidas que se pretendan implementar en el terreno económico y político. Por lo que es indispensable construir, a través de los canales de información, nuevos valores que produzcan una nueva visión cotidiana sobre nuestras personas, nuestras vidas, nuestra nación, nuestra historia y sobre la misión del hombre en el planeta tierra.

De lo contrario, se intentará implementar un proyecto de desarrollo material de la sociedad mexicana, sin un programa racional colectivo que lo respalde. Esto implicará gobernar sin bases mentales, pues se intentará modificar el estómago, los brazos y los pulmones del país, sin transformar la cabeza social, lo cual, creará un gobierno descerebrado. Esto es, el ejecutivo gobernará en una atmósfera esquizofrénica pues la cabeza del ente social, en el mejor de los casos, pensará en los valores de las exquisiteces sensoriales, mientras el cuerpo masivo luchará por sobrevivir en el crudo remolino de la realidad nacional.

Es por ello, que en esta fase de acelerada integración de los procesos culturales nacionales a la dinámica de centralización y globalización de las economías mundiales más avanzadas, es una obligación prioritaria de existencia del Estado Mexicano el que no abandone el uso y la creación de los procesos de comunicación

20 Datos presentados en el programa radiofónico de Tomás Mojarro, Palabras sin reposo, transmitido por Radio UNAM el 25 de abril de 1989. 
y cultura a los dictados salvajes de las libres fuerzas del mercado, que lo que buscan, en última instancia, es la permanente acumulación de capital; sino que planifique el funcionamiento de éstos para producir una nueva cultura cotidiana que propicie el desarrollo y la sobrevivencia del país. De lo contrario, si no proyectamos el uso de los canales de difusión y en especial de la televisión, alrededor de un proyecto de transformación mental para el crecimiento de nuestra sociedad, de nada servirá la realización del resto de las reformas modernizantes que ha impulsado el actual Estado Mexicano, pues el cerebro del país estará desvinculado de su cuerpo social; con lo cual, nuestra nación tarde o temprano se volverá a desmoronar, y cada vez más, con mayor intensidad. 